\title{
LA VIRTUALIZACIÓN DE LA SOCIEDAD
}

\author{
Francisco Javier Tirado Serrano \\ Universitat Autònoma de Barcelona \\ Franciscojavier.Tirado@uab.es
}

Había un niño que avanzaba, cada día, y el primer objeto al que miraba, en aquel objeto se convertía.

Walt Whitman

La belleza de estos versos reside, especialmente, en el misterio que encierran. El niño de Whitman mira una flor, y en ella se convierte, observa un árbol, y en él deviene, se fija en una niña, y en ella se transforma. Resulta curioso que el poema hable de avanzar. Porque el niño, cada día, avanza. La lectura más inmediata y simple nos hace pensar que se mueve. Pero el verso admite una segunda. El avance es ese devenir continuo: la transformación permanente. El niño de Whitman no se desplaza espacialmente, pero avanza, porque está-ahí y, a la vez, está-allá, convertido en otro, en ese otro que sus ojos no dejan de observar.

Pero podemos destruir esta belleza, preguntándonos por el interrogante analítico que encierran los mencionados versos: ¿cómo se convierte el niño en el objeto que observa? Y hay varias respuestas:

-Con la imaginación

-Con el error de definirse como objeto

-Con la elaboración de un relato en el que ocupa la posición del objeto

-Con un ritual ex-tático

-Con una sustancia lisérgica

-En un entorno virtual/ que produce simulaciones/ en el ciberespacio (internet)

Una palabra glosa todas las posibles respuestas: virtual. El niño de Whitman se convierte en el primer objeto que mira: de manera virtual. Además, la mencionada lista tiene otra propiedad, muestra las tres polaridades que para algunos autores son propias de este concepto.

\section{La insoportable densidad de lo virtual}

La primera polaridad distingue entre lo virtual en el sentido común y lo virtual en sentido estricto. Virtual, muchas veces, es sinónimo de error, ficción o no real. Mas, en sentido estricto, conviene recordar que virtual proviene del latín virtus, que quiere decir, fuerza o energía inicial, y como prima hermana tiene a la virtud, la capacidad o actividad de producir efectos. Si se consulta cualquier diccionario canónico, por ejemplo, el de la real academia española, se observará que virtual aparece en su primera acepción como un adjetivo, es decir, es una palabra que califica, es un término que 
indica la virtud (fuerza o potencia) de producir efectos, aunque no los produce de manera presente. Es decir, el efecto es real, pero no actual, se desplaza al futuro, al pasado, es intangible, no es visible. Lo virtual es una virtud que acompaña al ser humano desde siempre, es tan antiguo como éste, y aquí tenemos la segunda polaridad.

La que distingue lo virtual en sentido amplio de lo virtual en sentido restringido. Los mitos, los rituales religiosos, las experiencias lisérgicas, el teatro, la literatura, el cine o la televisión son precursores de la realidad virtual. Han creado mundos de ficción en los que hemos vivido, con los que hemos soñado y que no son otra cosa que mundos virtuales. Ahora bien, estos mundos virtuales imaginarios, míticos, trascendentes, son un tanto diferentes a los mundos virtuales tecnocientíficos, los creados a partir de la interacción de artefactos tecnológicos que alteran nuestras percepciones y son capaces de trasportarnos o ponernos ante otros mundos. Pero, también, habría que atender a una tercera polaridad:

La que diferencia entre lo virtual tecnocientífico y lo virtual producido en y gracias a las tecnologías de la información y la comunicación. A este último polo, Echeverría, por citar algún autor, lo denomina infovirtual. También es un mundo virtual tecnocientífico, pero sería una concreción o especificación. En la actualidad, prácticamente, todo mundo virtual tecnocientífico es infovirtual.

Los mundos virtuales tecnocientíficos son la característica de nuestro presente. Hace años el momento epocal que vivíamos se denominaba habitualmente capitalismo tardío, en los ámbitos económicos y políticos, y postmodernidad, en ámbitos culturales. Ahora se habla de globalización, en la literatura de origen e influencia anglosajona y de mundialización en la de corte francófono. No obstante, nuestro presente es la era de la virtualidad tecnocientífica. No afirmo que no exista un movimiento sin fronteras de información, mercancías, bienes, capital y personas... Pero si que todo eso, nos llega a nuestras prácticas más cotidianas, más inmediatas, a través de esta virtualidad tecnocientífica. El caso de la información es paradigmático. Pero se podría comentar otro tanto de la circulación de personas, capitales, etc.

Los mundos virtuales tecnocientíficos constituyen una extensión o un nuevo tipo de realidad. Son una suerte de tercer entorno. Los entornos son los ambientes, lo que nos circunda y en lo que vivimos. Tal entorno se sumaria al que representa la ciudad y al que significó la naturaleza.

\begin{tabular}{|c|c|}
\hline NATURALEZA Y POLIS & ENTORNO TELEMÁTICO \\
\hline 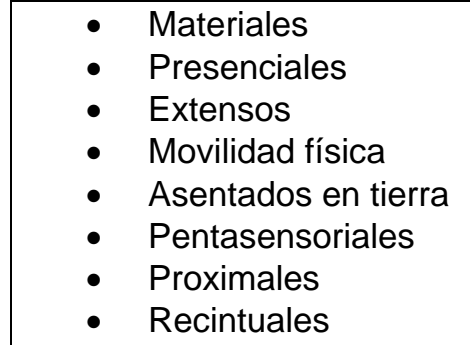 & $\begin{array}{ll}\text { - } & \text { Informacional } \\
\text { - } & \text { Representacional } \\
\text { - } & \text { Eomprimicos } \\
\text { - } & \text { Movimiento electrónico } \\
\text { - } & \text { Bisensorial } \\
\text { - } & \text { Distal } \\
\text { - } & \text { Reticular }\end{array}$ \\
\hline
\end{tabular}

Los mundos virtuales tecnocientíficos son sistemas que crean mundos artificiales, en ellos se puede entra, navegar, y manipular objetos. Distinguiría entre una inmersión dura y otra blanda. La primera 
habla de una percepción completa y total en el mundo virtual, sería la más típica de la realidad infovirtual, que busca un efecto total sobre nuestros sentidos. La segunda es una inmersión que combina el estar dentro y estar fuera, es una inmersión en la que somos actor y espectador. Estamos dentro, pero guardamos distancia. Sería la habitual en nuestra vida cotidiana, la que se da ante un ordenador, etc.

Estos mundos se pueden habitar, en ellos las experiencias que se producen en esta realidad infovirtual son reales. Se dan en tiempo real y permiten la repetición perfecta. Operan gracias a la universalidad del código base, son un enlace operativo entre imagen y lenguaje, facilitan la calculabilidad y se constituyen gracias a simulaciones a partir de matrices numéricas. Pero no por eso, dejan de ser un ars inveniendi, en él se crean entornos, objetos, personajes, relaciones...

En suma, lo virtual, en la realidad infovirtual, se transforma y adquiere otros estatus:

a) lo virtual como otro existente, un algo que existe, lo virtual aumenta, amplia y extiende la realidad

b) lo virtual-comunicación, permite la interacción, en tiempo real, es un método científico, pedagógico, de producción, tiene la capacidad de sintetizar imágenes creadas en tiempo real.

c) lo virtual inmersión, es un algo que genera la sensación de un estar-ahí-dentro

Cuando se menciona la expresión "entorno o mundo virtual" inmediatamente aparecen otras tres que deben comentarse, me refiero a la noción de realidad virtual, la de ciberespacio y la de simulación.

\section{Realidad Virtual}

La realidad virtual (RV) ha cristalizado como el fruto de diferentes fuentes y disciplinas de trabajo que provienen del campo de la ciencia y la tecnología, como pueden ser: la informática, las matemáticas, la robótica, la física, la tecnología de la guerra, la ingeniería aerospacial... Sin embargo, la informática es el campo de conocimiento que ha abanderado su creación y desarrollo.

Se han dado multitud de definiciones de RV. Y, curiosamente, siempre recurren a metáforas. Algunos ejemplos populares son: "ventana mágica que asoma a otros mundos"; "ángulo diferente de la realidad"; "espacio de apertura de nuevas posibilidades para entender la naturaleza, la realidad, el mundo"; "teatro de la experiencia"... Pero ¿cómo son estas metáforas?, ¿qué tienen en común? Pues fundamentalmente establecen analogías que se valen de significados relacionados con ideas de apertura, novedad, diferencia, o de un cambio de coordenadas espacio-temporales a otras en las que la relación espacio temporal actúa de forma diferente. Las características o implicaciones más importantes de la RV son:

\section{a. La abolición de la dicotomía: real-irreal}

Con la llegada de la RV la dicotomía, entre real-irreal, los límites claramente definidos, las fronteras nítidas que separaban y hacían antagónicas estas dos entidades se desdibujan y difuminan de forma definitiva. Esto no implica que la RV desvirtúe el significado de cada noción, puesto que existen contextos, ámbitos, a los que se les confiere la cualidad de "real", y en esta categoría se les incluye, y otros que pertenecen al mundo de lo irreal. Es decir, la RV no elimina la realidad o irrealidad como tales, sino que lo que erradica es la dicotomía, la separación, el límite que existía entre ellas. Con la irrupción de la RV aparecen formas híbridas entre lo que constituye la realidad y lo que constituye a lo 
no real o a lo virtual, porque ella misma, la RV, esta configurada por una mezcolanza de ambos espacios.

En la RV las personas llevan a cabo acciones, desarrollan experiencias, entablan relaciones, interaccionan, construyen y reconstruyen su identidad. Las personas, en definitiva viven en la RV, y estas vivencias dependen íntegramente de las simulaciones que les ofrece esta realidad. Esta vida, perfectamente real, en la simulación es lo que hace que la RV desafíe la dicotomía real-irreal, y lo que cada polo de la dualidad permite y posibilita.

Podemos encontrar tres elementos que caracterizan ese estatus:

- la RV es compartida

- la RV está al lado del mundo físico.

- RV se parece a la producción artística.

La RV es compartida: La navegación por un escenario virtual casi nunca es un acto individual y solitario de inspección y vivencia. Casi siempre es un acto colectivo, algo que se realiza en compañía de otras personas, compañía que no es física pero que es percibida, sentida como algo colectivo, como algo que se realiza de forma conjunta, junto a otros/as. Y es esta percepción de compañía, de acto colectivo lo que los usuarios de estos entornos valoran. La interacción, la relación, el contacto con otras personas que participan del espacio virtual son los elementos que convierten a la RV en una experiencia compartida.

La RV convive con el mundo físico. Real y virtual se convierten en realidades permeables, traspasables, capaces de aportar la una a la otra experiencias enriquecedoras, prácticas gratificantes, costumbres y hábitos nuevos, etc.

La RV como una obra de arte. Los objetos de la RV se pueden manipular, se pueden crear siguiendo la intuición del/la creadora, el efecto es estético, en la medida en que el resultado se puede visualizar, contemplar y valorar como si de una obra artística se tratase. La creación de RV no sigue unas normas estrictas de diseño, sino que se puede jugar, combinar, componer según el gusto de la persona que lo esté diseñando. La motivación también es estética. Se crean mundos y realidades a partir de parámetros puramente plásticos. Es decir, que buscan exclusivamente el deleite y el disfrute del usuario; convirtiéndose, así, en un nuevo universo de experiencias.

\section{b. La RV como despliegue experiencial}

La RV permite introducirse en un mundo artificial, explorarlo, manipularlo, tocarlo, modificarlo. En ocasiones posibilita ser el/la creador/a, en otros sólo el/la consumidor/a de la propia experiencia.

Frecuentemente se presenta la RV como un instrumento de amplificación de la inteligencia, como medio para expandir la percepción humana. Para algunos autores, éste es un principio fundamental de la RV. La experiencia cobra una importancia capital en la naturaleza de la RV, la experiencia de estar en un lugar concreto, en un mundo que es virtual. Por esta razón en muchas ocasiones se la compara con un "teatro de la experiencia" o con un "simulador".

El eje en torno al cual gira cualquier RV es siempre la experiencia humana, la puesta en práctica de introducirse en un mundo que no pertenece a la realidad cotidiana de las personas. Por esta razón en el desarrollo de la tecnología informática no importa tanto el funcionamiento de los ordenadores sino 
el modo en que se diseñan para ser usados por las personas, lo que importa es la interfaz personaordenador, la relación entre ellos dos, su punto de contacto. De esta manera, la RV emerge como una importante y valiosa interfaz del ordenador. La RV, los mundos virtuales constituyen la cristalización de la relación entre las personas y los ordenadores. Lo relevante en la RV no es una cuestión de bits, ni del hardware o el software del ordenador, ni de los avances tecnológicos que se produzcan en torno a estos elementos. Lo realmente importante en la RV es el punto de contacto, de conexión que ella facilita, provoca, genera entre las personas y sus ordenadores, puesto que cualquier mundo virtual es un mundo que se construye no desarrollando determinados programas informáticos, sino haciendo uso, utilizando, mirando, caminando, tocando, manipulando ese mundo. En definitiva, la RV existe gracias a, por y para esa relación. Un ejemplo de esto lo podemos encontrar en uno de los utensilios más utilizados cotidianamente por nosotros/as: "el ratón". Para entrar en un programa o en un documento no necesitamos teclear toda una serie de instrucciones, lo hacemos mediante un gesto de nuestra mano, mueves el ratón hacia una determinada dirección y colocas el cursor sobre el programa deseado. El ratón es uno de los elementos paradigmáticos que representan el vínculo estrecho entre persona y ordenador que promueve la RV.

\section{c. Inmersión y Navegación}

La tercera de las características más importantes de la RV queda representada en las dos ideas clave que detenta este fenómeno: la inmersión y la navegación.

La idea de inmersión tiene que ver con el uso de determinadas tecnologías (como por ejemplo la óptica, la estereoscopía, la electrónica) con el objetivo de configurar modelos que puedan crear la ilusión o sensación de estar dentro de un escenario (construido por ordenador). La noción de navegación consiste en crear un determinado modelo por ordenador, un espacio, ámbito, mundo o escenario y ofrecer la capacidad a la persona de poder desplazarse, moverse, tocar, deambular como si se encontrase dentro de él, viviéndolo y construyéndolo.

\section{Ciberespacio}

La noción de ciberespacio nace en la novela de William Gibson "Neuromante" y es descrito como una "alucinación consensuada". Su novela fue pionera por la posibilidad que abría al acercamiento a las novedosas y sugerentes realidades informáticas. Ofrecía a sus lectores/as imágenes atractivas y fascinantes de lo que suponía sumergirse y navegar por mundos simulados. El protagonista de su obra, un héroe futurista, se trasladaba, recorría una matriz constituida por conexiones entre diferentes instituciones. El sueño de su héroe consistía en pasar a formar parte, confundirse, hibridizarse con las formas de vida virtuales, digitales que conformaban su ciberespacio. Sin embargo el ciberespacio es mucho más que unas determinadas líneas de códigos, un conjunto de bases de datos y de señales eléctricas.

El ciberespacio es una producción, una construcción conjunta, realizada de forma cooperativa gracias a las posibilidades que ofrece la tecnología informática y los intereses, gustos, preferencias... de sus creadores/as y usuarios/as. Cualquier escenario virtual es posible porque el ordenador, conectado a la red, transforma su modelo digital en un patrón correcto de puntos de luz que vistos desde una perspectiva adecuada y mezcladas adecuadamente con ondas audibles, convence al/la "navegante" de que más o menos está experimentando un mundo virtual. 
La literatura generada en torno al ciberespacio afirma que éste se está convirtiendo en la última frontera a explorar, y que la realidad virtual es su medio. Para describir esta noción se han utilizado variadas expresiones: ciberia, espacio virtual, mundos virtuales, dataespacio, dominio digital, ámbito electrónico, esfera infográfica...

El sueño de McLuhan (¿utópico o distópico?) halla las condiciones de posibilidad de su advenimiento en la emergencia del ciberespacio. Por tanto, los debates al uso en la academia sobre el fenómeno de la globalización no deben ni pueden olvidar el análisis sobre este nuevo tipo de realidad.

\section{Simulación}

¿Cómo opera la RV, qué posibilita la navegación y exploración del ciberespacio? Pues generando simulaciones. Cualquier pequeña actividad que pueda realizar un ordenador puede considerarse como simulación. Simulación no es imitación, ni representación, ni una ficción, es otra cosa.

Las simulaciones ya forman parte de la cotidianeidad diaria de muchos y muchas de nosotras, una de las simulaciones más cotidianas es la que nos encontramos cuando queremos entrar, manejar y hacer uso de nuestro ordenador: nos encontramos un escritorio, nuestros documentos organizados en carpetas, papeleras, programas... Este mecanismo icónico de funcionamiento del ordenador la introdujo en 1984 la empresa Macintosh, sin embargo esta práctica no se limita ya al uso de este tipo de ordenadores, sino que se ha extendido de forma universal en todos los ordenadores personales. Aprendemos a utilizar los programas, nos familiarizamos con los diferentes "sucesos" informáticos gracias a los iconos que nos encontramos en la pantalla del ordenador, nuestras carpetas virtuales son en muchas ocasiones más útiles que las que existen materialmente...

Para algunos autores existirían tres importantes efectos desarrollados gracias a la simulación:

- Efecto Disneylandia

- Efecto del cocodrilo artificial

- Efecto de la sobrevalorización de la experiencia.

El efecto Disneylandia consiste en hacer que las experiencias desnaturalizadas parezcan reales. El efecto del cocodrilo artificial hace que lo falso parezca más persuasivo que lo real. En ocasiones, las personas que participan activa y frecuentemente de escenarios virtuales llegan a valorar sus experiencias y relaciones en los mundos virtuales como más reales y apasionantes que las que se producen en sus vidas ordinarias en la realidad de "lo real". El tercer efecto consiste en que la experiencia virtual puede ser tan persuasiva que creamos que dentro de ella hemos conseguido más de lo que pensamos.

Pero esta línea de argumentación soslaya lo que serían los dos efectos más llamativos que connota la simulación: a) introducirnos en una era o momento en el que el referente parece perder toda su antigua relevancia; y b) el privilegio de la codificación digital.

\section{a. La desaparición del referente}

Autores como Baudrillard han definido la simulación como la generación a partir de modelos de algo real que no tiene ni origen ni realidad. Concretamente, ha denominado a este efecto hiperrealidad. La dimensión de la simulación es la miniaturización, lo real se produce a partir de células miniaturizadas, 
de matrices, de memorias, de bases de datos, de modelos por encargo; y a partir de ahí lo real puede ser reproducido un número indefinido de veces. La simulación, de esta manera, es su propia referencia, al eliminar los referentes como punto de partida para generar "lo real". Así, la simulación es una operación nuclear, tiene valor en sí misma, tiene un sentido por sí misma y no es el reflejo de nada, no es especular.

Por otro lado, también es una operación genética y no discursiva, despliega un marco experiencial que desborda al discurso, lo meramente discursivo. La simulación, como ya hemos dicho es una síntesis de modelos. Su lógica se basa en la precesión de los modelos sobre los hechos. El modelo siempre es anterior a cualquier definición que se pueda dar o a cualquier configuración que encontremos de hechos. Los hechos ya no tienen trayectoria propia, se producen, se incrustan, tienen valor en la intersección de estos modelos. Esto es así hasta el punto que un sólo hecho puede ser engendrado por todos los modelos a la vez.

De este modo, la simulación nos introduce en el universo posmoderno por excelencia. Autores como Jameson, por ejemplo, han argüido que lo que caracteriza a eso que llamamos posmodernismo es su preferencia por la superficie más que por la profundidad, la preferencia por las simulaciones frente a la búsqueda de lo real. Más allá de la superficie y la simulación no hay nada. Así, para Jameson la simulación abre un paradigma de la superficie frente a ese paradigma de la profundidad que había caracterizado nuestra modernidad, paradigma obsesionado por la búsqueda o descubrimiento de referentes ocultos bajo lo real.

Si bien, esta operación de búsqueda en las profundidades de los referentes ocultos es la operación que caracteriza la modernidad, la operación que ahora parece traernos el paradigma de la superficie es el bricolaje incesante. Este bricolaje que implica la simulación produce un movimiento que va del seguimiento de unas reglas y normas dictadas y preestablecidas, a la posibilidad de hacer bricolaje, de operar, manipular los escenarios simulados. Esta operación de bricolaje posibilita la relación, interacción con lo simulado, permite la creación a través de la prueba, el ensayo, el tanteo en las realidades simuladas. Se ha denominado al estilo de operar mediante bricolaje "dominio blando". Este dominio se caracteriza por un estilo flexible, no jerárquico, en completa conexión con el objeto de estudio, y en el que la negociación, la relación y el compromiso son los valores relevantes. Éste es el dominio que caracteriza al funcionamiento del ordenador en la actualidad, un estilo que tiene que ver sobre todo con la simulación y la navegación. De esta manera, la simulación se caracteriza por la flexibilidad, la manejabilidad, la maleabilidad, en contraposición con la rigidez, lo estricto o inflexible. Estas últimas características eran las propias de la imagen, ya obsoleta, que se tenía del ordenador concebido como calculadora, en la que para funcionar el/la usuario/a tenía que introducirle una serie de órdenes y seguir un conjunto de reglas.

\section{b. El privilegio de la Codificación Digital}

La codificación digital de las imágenes es la condición de posibilidad de la simulación. El universo de posibilidades de la simulación está constreñido y limitado por las posibilidades que permite la codificación numérica. Cualquier imagen o información puede ser traducida en secuencias de números. Esta traducción numérica se puede expresar en un lenguaje binario, es decir, en forma de ceros y unos. Toda información o imagen explícita y mesurable es susceptible de ser representada por este sistema. El interés de este sistema binario es triple. En primer lugar señala que los dispositivos técnicos pueden registrar y transmitir números codificados en lenguaje binario; en 
segundo lugar las informaciones codificadas numéricamente pueden transmitirse y copiarse de manera casi indefinida sin ninguna pérdida de información; y en tercer lugar, los números codificados de manera binaria pueden ser objeto de cálculos aritméticos y lógicos a través de circuitos electrónicos especializados. Sin embargo, la codificación numérica sin más es absurda e inservible, es necesario que la codificación numérica y el tratamiento binario de la información, sea traducido en sentido inverso y pueda manifestarse bajo la forma de textos, imágenes, sonidos, sensaciones, en definitiva bajo la forma de una simulación. La codificación numérica es un punto de paso obligatorio para la posibilidad de simulación, para que ésta pueda existir, tener lugar, manifestarse, puesto que sin ella, el tratamiento de la información de una manera tan efectiva, automática, perfecta, compleja, eficaz y rápida sería del todo imposible. Además permite que las informaciones, imágenes puedan se tratadas, manipuladas, modificadas, reconstruidas y reconfiguradas de manera fácil, cómoda y rápida.

La simulación nos incorpora inmediatamente a una realidad que presenta tres características fundamentales. La primera nos indica que la simulación opera con dos niveles, el nivel usuario, que es un nivel básicamente visual, de uso amistoso, fácil de manejar, intuitivo, compuesto por iconos e imágenes que supuestamente representan algo; y el nivel invisible, que es el nivel de las matrices numéricas y que es un nivel inaccesible para el/la usuario/a. La segunda característica consiste en que la simulación remite a materialidades fluidas, que quedan constituidas por el conjunto de codificaciones numéricas que viajan y se desplazan a través de transmisiones telefónicas en cuestión de segundos. Y la tercera característica que nos muestra cómo la simulación está poblada de presencias invisibles, presencias que no son físicas, pero que hacen sentir a las personas que se encuentra junto a otras muchas, a las que no puede tocar, pero que sí puede sentir.

Realidad virtual, Simulación y ciberespacio son tres nociones articuladas en una misma totalidad, ninguna de las tres puede existir por separado en la forma en que se manifiestan actualmente, se necesitan las unas de las otras... Al definirlas hemos visto que uno de los puntos más recurrentes en todas es la promesa de construir mundos, escenarios y realidades de las que participar y a las que poder modificar. Esta puerta abierta a la creación de "experiencias" es el umbral, también, para generar otras formas de concebir o interpretar fenómenos de la relevancia de la identidad, comunidad, relaciones, interacción, realidad, humano, etc. Si nos quedamos en el plano de las ideas y las definiciones es posible trazar fronteras entre ellas: hay RV, sin ciberespacio y sin simulaciones: por ejemplo el cine; hay ciberespacio sin RV o simulaciones: por ejemplo las bases de datos; y hay simulaciones sin RV ni ciberespacio: por ejemplo el escritorio de un ordenador. Pero, si observamos a nuestro alrededor encontramos que están naciendo formas sociales que emergen a partir de la interrelación de RV, Ciberespacio y Simulación. Tales formas, al mismo tiempo, cosifican, intensifican, objetivan, y hacen más indiscernible la relación entre estas entidades.

\section{La insoportable levedad de lo virtual}

Internet está en todas partes, pero no del mismo modo Christine Hine

La primera parte de esta afirmación coincide con todo lo dicho anteriormente: Internet es un fenómeno importante, que nos pone sobre la pista de transformaciones que están ocurriendo en 
nuestro presente. Pero la segunda introduce matices interesantes, esas transformaciones están por todas partes y tienen peculiaridades, se dan de distinta manera.

Esta sentencia forma parte de un grupo de autores que sostienen que nuestro presente está afectado por un movimiento general de virtualización, obviamente, pero éste es algo más que la mera informatización. Se huye de una lectura apocalíptica y tecnológica del fenómeno de la virtualización. Un buen ejemplo es la obra de Pierre Lévy y el tipo de aproximación que desarrolla. La virtualización es una continuación o momento dentro de la hominización. La virtualización no es buena, ni mala, ni neutra. Es un movimiento general de convertirse-en-otro.

Para este autor no existe oposición entre lo real y lo virtual, ésta se da entre lo virtual y lo actual, del mismo modo que lo real se opone a lo posible.

\begin{tabular}{|l|l|l|}
\hline Real/Posible & Actual/Virtual \\
\hline - Lo posible es una copia de lo real, por & & \\
tanto, está constituido, su lugar es el & & Lo virtual no está totalmente \\
limbo, espera ser realizado. & - Es un nudo problemático, cruce de \\
- Se realiza sin que nada cambie & $\begin{array}{l}\text { fuerzas y tendencias. } \\
\text { - Estático }\end{array}$ & $\begin{array}{l}\text { Debe ser actualizado } \\
\text { - Se actualiza por diferenciación. }\end{array}$ \\
\hline
\end{tabular}

Además, lo virtual se inserta en la estructura del acontecer, del acontecimiento.

Acontecimiento: tiene dos dinámicas

\begin{tabular}{|l|l|}
\hline Actualización: & Virtualización: \\
-territorialización & -desterritorialización (salir-de-ahí) \\
-interpretación aquí y ahora & -separación \\
-solución particular & -abrir una problemática \\
& \\
\hline
\end{tabular}

Un vector con dos polos. En la actualización se produce la solución a un problema, hay creación, innovación, invención. Aparece una forma a partir de una configuración de fuerzas. Aparece algo nuevo, diferente. En la virtualización se produce una mutación de la identidad, un desplazamiento del centro de gravedad ontológico del objeto considerado. Es irreversible en sus efectos e implica indeterminación en los efectos que abre. En la actualización pasamos de un problema a una solución. En la virtualización pasamos de una solución a otro problema.

Virtualización:

-cambio de identidad

-paso de una solución particular a una problemática general

-transformación de una actividad especial y circunscrita a un funcionamiento deslocalizado, desincronizado y colectivizado 


\section{3. ¡Siempre hemos sido, siempre seremos, virtuales!}

Tres virtualizaciones han creado lo humano: el lenguaje, la técnica y el contrato. La tesis fuerte de Lévy consiste en afirmar que los seres humanos se constituyen en y por la virtualización. Hay un permanente proceso de autocreación de la humanidad. No obstante, éste se ha visto en el presente acelerado hasta límites hasta ahora insospechados.

Precisamente, la mencionada aceleración no permite mantener la distinción entre los tres tipos de virtualización. Los tres se mezclan en una espiral que los torna indistinguibles.

El planteamiento del autor presenta una ventaja y dos importantes lagunas. Su reconceptualización de fenómenos como el lenguaje (virtualiza especialmente el tiempo real y permite que emerjan otras temporalidades desligadas del aquí-y-ahora), la técnica (virtualiza la acción) y el contrato (virtualiza las relaciones cara-a-cara), muestra que esas temáticas no está agotadas en el pensamiento social. Todavía se pueden repensar o pueden abrir nuevos espacios para la reflexión. Por ejemplo, desde la problemática de lo virtual se redescubren algunas funciones de lo lingüístico o comprendemos mejor la distinción entre práctica y técnica. Mas Lévy no resuelve satisfactoriamente ni el problema de la afectividad ni el de la subjetividad. Nos recuerda que la primera es fundamental en los colectivos inteligentes. Es más, sin afectividad, resulta difícil diferenciar entre colectivos inteligentes y otros tipos de inteligencia colectiva. Y respecto a la subjetividad, realiza el esfuerzo de definir un sujeto colectivo, global, que, al mismo tiempo, respetaría las singularidades de todas las personas que participasen en su constitución, o sea, no queda claro en qué consistiría o a través de qué mecanismos pasaría la relación entre ese sujeto colectivo y las singularidades que lo integra.

La relación virtualización-hominización se asienta, aparentemente, en los procesos de virtualización del leguaje, la técnica y el contrato. Estos presentan un denominador común: la lógica gramáticadialéctica-retórica. No obstante, existe un detalle determinante en su propuesta que él pasa por alto o valora escasamente, la noción de tipo-móvil. Éste es una unidad o que permite la desterritorialización que significa la operación gramatical. Además, señala que no toda desterritorialización es válida o posible, ni se da de cualquier modo. Resulta imprescindible y necesario la aparición de un tipo-móvil para que se propicie una fenómeno de desterritorialización. La peculiaridad de nuestro presente es la presencia masiva de un único tipo-móvil: la información. Ésta por todas partes, es válido para cualquier operación gramatical en el interior de cualquier fenómeno de virtualización.

La información es un objeto que presenta algunos problemas que Lévy no acaba de resolver. Por ejemplo, necesita cierta materialidad. La información circula, se mueve velozmente, pero accedemos a ella gracias a una infraestructura, que es del todo punto inevitable si se quiere trabajar con ese objeto. En ella encontramos ordenadores, procesadores, cables, etc., que se fabrican con ciertas materias primas, con recursos que pueden llegar a escasear. En este punto conviene aclarar que información y materialidad no son dos conceptos opuestos o antitéticos. La información necesita condiciones materiales para su retenimiento, circulación, crecimiento... pero ésta es algo más que meros datos. Es acción, movimiento, es in-formación, da forma, y genera efectos que son absolutamente materiales. No habría, por tanto, distancia entre la información y la materialidad. 


\section{Las reglas de la sociedad virtual}

Dentro de poco se traducirá al castellano un libro que es un fruto de un enorme proyecto de investigación que se puso en marcha en Inglaterra hace varios años y que se enfrenta al interrogante de describir qué está pasando en nuestro presente con las tecnologías virtuales. El título del proyecto es muy sencillo, se titula simplemente ¿sociedad virtual?, y se enfatiza precisamente el interrogante. Es un estudio enorme en extensión, han participado decenas de universidades británicas, investigadores, etc., y en intensión, se han analizado multitud de aspectos de la realidad británica relacionados con las tecnologías virtuales: cuestiones sociales, políticas, históricas, económicas, legales...

Pues bien, el estudio abre con la definición de cinco grandes temas analíticos que corresponden a otras tantas reglas para aprehender el sentido de una sociedad virtual. Creo que esas reglas o ejes también están presentes en los trabajos que se presentan en este simposium. Son las siguientes:

Regla $n^{0}$ 1: la aceptación y utilización de las nuevas tecnologías depende de forma crucial del contexto social local. El contexto cultural es determinante en la recepción y utilización de las tecnologías electrónicas.

Regla $\mathrm{n}^{\circ} 2$ : los miedos y riesgos asociados con las nuevas tecnologías están distribuidos socialmente de forma desigual.

Regla $n^{\circ}$ 3: las tecnologías virtuales son un complemento y no un sustituto de la actividad real. Las tecnologías electrónicas complementan y no sustituyen las prácticas y formas de organización ya existentes. Lo virtual extiende, amplía lo real, no se opone a la realidad.

Regla $n^{\circ}$ 4: cuanto más virtual, más real. Las nuevas actividades virtuales no sólo conviven con las actividades reales existentes, sino que la introducción y utilización de nuevas tecnologías virtuales puede estimular realmente una mayor actividad real equivalente.

Regla $n^{\circ}$ 5: cuanto más global, más local. Ese fenómeno denominado globalización o mundialización depende, evidentemente, de las tecnologías electrónicas, pero depende, especialmente, de la gestión local que se realiza de las mismas.

Personalmente, añadiría otra regla a esta lista que también es explícita en los siguientes trabajos, como ya he mencionado: virtualización no es igual a informatización. Lo virtual tiene que ver con la posibilidad de convertirse-en-otro, de salir de los ejes que definen una realidad, por tanto, lo virtual no es una novedad, el lenguaje puso en marcha fenómenos de virtualización del tiempo real y permitió que apareciesen otras temporalidades desligadas del aquí-y-ahora, la técnica, el artefacto tecnológico virtualizó la acción, la desligó del cuerpo y su entorno, la aceleró, etc.; y el contrato virtualizó las relaciones cara-a-cara, las hizo perdurar en el tiempo y en el espacio. 